\title{
THE ROLE OF PARENTS IN TALENTED YOUTH SPORT. DOES CONTEXT MATTER?
}

\author{
MÁRCIO DOMINGUES, CARLOS E. GONÇALVES \\ University of Coimbra, Faculty of Sport Sciences and Physical Education \\ Mailing address: Márcio Luís Pinto Domingues, University of Coimbra, Estádio Universitário, Pavilhão 3, \\ 3040-156 Coimbra, Portugal, tel.: +351 239802770, fax: +351 239802779, \\ e-mail: marcio.domingues@live.com.pt
}

\begin{abstract}
Introduction. The present study investigates the characteristics of the environmental factors that influence the structure of sport amongst young people; alongside this, the study also attempts to describe the influential role of parents in the development of sporting talent; finally, the study emphasizes the significance of parents' educational beliefs concerning the acquisition of life-long social skills through participation in sport in demanding competitive environments. Material and methods. 8 semi-structured interviews and 3 unstructured interviews were conducted among young people participating in a semi-professional club at national competitive level. A field diary was also collected. Results. Qualitative analysis revealed that: a) structural and organizational aspects, as well as the overall climate of the club, shape the behavior of young people in relation to social goals; b) parents play an important role as socializers in competitive environments; c) parents display a solid awareness of their own influence on the attitudes and behavior of young people. Conclusions. The findings highlight the important role of parents in sport participation in highly competitive environments. The study also shows contextual factors as predictors of the degree of youngsters' social and personal variables in performance levels. Implications for parental involvement in youth sport as well as future research directions are further discussed.
\end{abstract}

Key words: parenting, sport environment, youth athletes, ecology

\section{Introduction}

The involvement of parents, especially fathers, in youth sport undergoes cultural changes that are complex and have direct implications for families and father-child relationships [1]. Because millions of young people are involved in sport, the sport context is important to consider in developing the experiences of young people [2, 3]. Studies over the years have highlighted the importance of frame examinations of adolescent participation, behavior and social support in sporting contexts $[4,5]$. Sport evidently has significance for participants because it provides opportunities for interpersonal interaction and the development of social bonds with significant others [6]. It has been shown that other people influence youth participation in a motivational climate and support autonomy [5].

The present study is guided by Bronfenbrenner's BioEcological Theory (BET). The theory supports the notion that development is influenced not only by biological variables, but also by contextual factors, such as family, school, neighborhood, community, society, and the surrounding culture. Bronfenner claims that contexts can be more objective (e.g., income level) or more subjective, involving people's perceptions and experiences of the environment in which they live [7]. In a more recent approach using the PPCT model (Person-Proximal ProcessContext-Time), Bronfenbrenner shifts his focus to proximal processes. These processes could explain the connection between some aspect of the context (culture or social class, for example) or some aspect of the individual (e.g., gender) and provide an interesting result. They constitute the engines of development because it is by engaging in these activities and interactions that individuals come to make sense of their world [8].

Some researchers [9] have investigated parenting styles and multiple social interactions associated with youth sport parenting. From independent support to more control by parents, parenting practices and styles vary across different situations.

Recent literature has examined what kind of parental influence is exerted in competitive youth sport settings [10,11]. Research has focused on patterns of involvement related to pressure and directive behavior [12], compared to parental support for enjoyment of sporting and academic performance [13].

The influences of parents and the differing reasons parents may have for initiating their children's participation are major factors in youth sport experiences. Studying the psychosocial climate of sport, there is a growing interest in the way that specific parental behaviors are associated with positive outcomes for youth at different levels of talent development [14]. In other words, it is warranted to determine which relationships are central to parents' involvement in competitive youth sport, highlighting the influence of significant adults on young people's psychosocial development in the domain of sport [15].

It is therefore important to determine three aims of this research: first, to describe the significance of parental behavior in contrasting youth sport environments; second, to provide a de-scription of parental social support and its effects on youth be-liefs and expectations in these environments; and lastly, to inves-tigate parents' educational beliefs and the acquisition of lifelong social skills through sport participation in demanding competi-tive environments.

\section{Material and methods}

\section{Participants}

11 participants (8 semi-structured and 3 unstructured inter- 
views) were interviewed from a professional football environment during one sport season. These participants were selected deliberately after initial observations to determine which participants were more involved on a daily basis. The teams the researchers studied were squads of under-16s and under-14s, competing both at a national and regional level. After initial scrutiny, parents were then divided into two groups: 'assisting parents' (with no specific roles) and 'intervening parents' with directive and differentiated roles in the club. These participants were of widely varying ages and professional duties and their sons were athletes with a good competitive record, selected to play at the club.

\section{Procedures}

Preliminary meetings were conducted, which served to introduce the research and the underlying procedures to be held at each club. After the club's approval was given, successive visits were scheduled and a timetable was drawn up. Semistructured interviews always took place in the same room and researchers tried to maintain the same schedule of interviews, prior to training. Interviews were semi-structured to allow for the development of other issues concerning the club and the athletes, as well as to promote critical thinking about important themes.

Researchers made a careful evaluation of the study's ethical acceptability. Standard procedures (institutional review and approval, informed consent) were assured and the study was approved by the Ethical Committee of the Faculty of Sport Sciences and Physical Education. APA Ethical Guidelines for Research with Human Subjects served as a reference in the present study. Researchers made certain that parents had sufficient knowledge and understanding of the nature of the proposed research, the anticipated risks and potential benefits, and the requirements of the research, to be able to make an informed decision. The main researcher respected the individual's freedom to decline to participate in or to withdraw from the research at any time. Furthermore, after the data had been collected, researchers provided the parents with information about the nature of the study and attempted to remove any misconceptions that may have arisen. Finally, information obtained from the research was confidential and anonymity was guaranteed.

\section{Data collection}

For the purposes of the present study the analysis focused on the common and contrasting importance of parents as social agents participating in the study and an observation grill (more than 80 hours of direct observation). A field diary was used to categorize the amount of observations completed based on the theoretical framework (Tab. 1).

Parents' information was compared with that provided by other parents or directors until a consistent picture was established. The role of the researcher was to listen actively and to move the conversation forward by building on what each parent had to share. Throughout the interview process, the investigator ensured that the information elicited from each parent was fully understood.

The researcher was neutral regarding the content of the interview and at the end of each day all data were coded into useful blocks of information. The questions asked about the participants' actual behaviors were as precise as possible. Suggestive questions that influenced the direction of the responses were avoided. Informed consent was obtained from all participants and the interviews with the athletes and the parents lasted between 45 minutes and one hour and fifteen minutes. All interviews were tape-recorded and a full verbatim transcription of each interview was completed.
Table 1. Field descriptive analysis

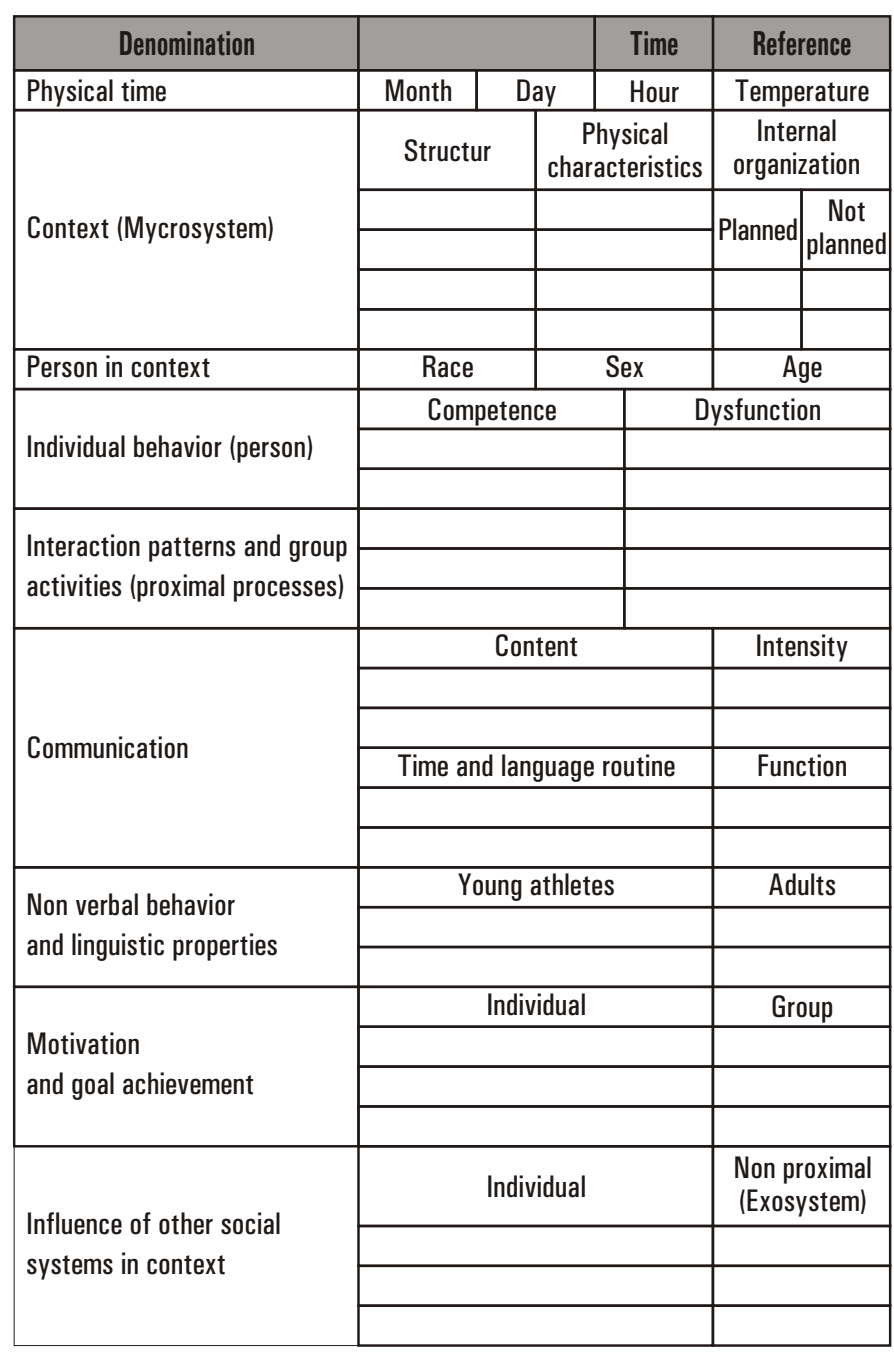

Note: Based on Bronfenbrenner \& Morris [22] and Bronfenbrenner \& Evans [8]

\section{Data analysis}

The analysis progressed to building an organizing system of categories that emerged from the semi-structured interviews [16]. A qualitative content analysis was used and it involved two processes: specification of the content of the semi-structured interviews; and the application of rules for identifying and recording these characteristics. Therefore, analysis started by coding the statements, with participants able to present their experiences in a flexible way as emerging data was subsequently coded.

As with all research methods, conceptualization and operationalization necessarily involve an interaction between theoretical concerns and empirical findings. The researchers had pre-defined codes that were elaborated, based upon literature review and the theoretical framework adopted [17]. Theme identification and categories emerged from the transcribed interviews, and deductive reasoning followed the hypothesized dimensions [18] (Tab. 2). The discussion of the results followed a separate analysis made by the researchers independently, and continued until a full consensus was obtained. An external researcher, expert in content analysis validated the coding process.

This combination of methods allowed for a cross validation of data. In fact, validation and credibility checks were an ongoing process [19]. Bias is inherent to qualitative data [20], and 
accordingly, internal validity was obtained through repeated observations, multiple repeated forms of data collection and posterior triangulation, i.e., interviews. Observation allowed for more internal validity [21]. In this way, researchers attempted to provide a dense, accurate description of the reality under study through the lens of a consistent theoretical frame work such as the BET and PPCT model.

Table 2. Dimensions, categories and group of responses of POC

\begin{tabular}{|c|c|c|}
\hline Critical dimensions & Categories & Groups responses \\
\hline \multirow{6}{*}{$\begin{array}{l}\text { Personal Development } \\
\text { and Self-Improvement }\end{array}$} & \multirow{2}{*}{$\begin{array}{l}\text { Opportunity for } \\
\text { construction social skills }\end{array}$} & Social skills sport \\
\hline & & Identity construction \\
\hline & \multirow{2}{*}{ Family integration } & Support relations \\
\hline & & Family structure and support \\
\hline & \multirow{2}{*}{ School integration } & School expectations \\
\hline & & School-club integration \\
\hline \multirow{5}{*}{$\begin{array}{l}\text { Proximal Processes } \\
\text { and } \\
\text { Social Interactions }\end{array}$} & \multirow{3}{*}{ Climate and values } & Group interaction \\
\hline & & Sport recognition \\
\hline & & Significant club relations \\
\hline & \multirow{2}{*}{$\begin{array}{l}\text { Social relations } \\
\text { and efficacy }\end{array}$} & \begin{tabular}{|l|} 
Club-athlete relation \\
\end{tabular} \\
\hline & & Adults role \\
\hline \multirow{9}{*}{$\begin{array}{l}\text { Sport Context } \\
\text { and Achievement }\end{array}$} & \multirow{3}{*}{$\begin{array}{l}\text { Identity } \\
\text { and experiences }\end{array}$} & Club history and community \\
\hline & & Professional sport \\
\hline & & Clubs status \\
\hline & \multirow{2}{*}{ Community integration } & Social characterization \\
\hline & & Subsidies and support \\
\hline & \multirow{4}{*}{$\begin{array}{l}\text { Organization } \\
\text { and structure }\end{array}$} & Structure and human resources \\
\hline & & Physical structure and conditions \\
\hline & & Sport mobility \\
\hline & & Logistics and organization \\
\hline
\end{tabular}

\section{Results}

The results are discussed in terms of integration with Bronfenbrenner's ecological theory [22]; BET guided this research and proved useful in discriminating the results, according to the four main concepts of Bronfenbrenner's model, Person, Proximal Processes, Context and Time (PPCT). Content analysis provided 3 critical dimensions and 8 underlying categories through a deductive analysis of the inductive blocks of information that emerged and the group of responses.

Table 3. Coding of the semi structured interviews

\begin{tabular}{|c|c|}
\hline Code & Meaning \\
\hline \multicolumn{2}{|c|}{ Professional Oriented Club (POC) } \\
\hline POC-1 & Professional Oriented Club-Parent Youth Coordinator \\
\hline POC-2 & Professional Oriented Club-Parent Under 17 Physical Education \\
\hline POC-3 & Professional Oriented Club-Parent Under 16 Director \\
\hline POC-4 & Professional Oriented Club-Parent Under 18 Civil Engineer \\
\hline POC-5 & Professional Oriented Club-Parent Under 18 Director Automobile Company \\
\hline POC-6 & Professional Oriented Club-Parent Under 16 Coach \\
\hline POC-7 & Professional Oriented Club-Parent Under 18 Director \\
\hline
\end{tabular}

\section{Personal development and self improvement}

Opportunity for skill construction

In the POC, the parents' perceptions of contextual practice influences social behaviors and attitudes toward sport participation in a way that differs greatly from that of the previous clubs that they attended: "...when they enter the club, they change completely their behavior and become super dedicated, committed..."(POC-1).

There exists a set of interpersonal social skills that parents point out in relation to participation in sport and the education of young people, with the capacity of teaching life-skills to employ in the community and in diverse microsystems, for example, skills like resilience: "...sport for them is a teaching tool to surpass some of the difficulties that life brings..." (POC-5); a sense of belonging: "I can see perfectly the kids who have team spirit (...) they are more sociable, much more interactive" (POC-2); a sense of responsibility, respect and discipline: “...respecting others is important for me (...) they have to know how to be part of a group..." (POC-3); social equilibrium: "...having the opportunities to be with friends and taking pleasure in what they like doing (...) is fundamental for their equilibrium..."(POC-5).

"...sport practice prepares them for society, not just in relation to rule fulfillment, but also how to deal with the adversity factor, and our society nowadays is more and more aggressive in that respect" (POC-2).

Parents identify positive attitudes and behaviors in practicing sport as it is the most important activity in their (youngsters') daily life, “...the thing that I notice is that when he doesn't have soccer he is really impatient (...). Football is a fantastic complement to his life; it is what he likes to do best"(POC-5).

\section{Family integration}

In both environments the importance of family structure on young people's sport attitudes and behaviors is consensual and assumed: "We, quite often, evaluate youngsters in the same way when they have completely different family backgrounds, completely different...” (POC-4). Parents are more prominent in this respect, while school is also a space of individual growth "Home is the first place where they must have some basic principles and ethical imperatives which they should take with them...” (POC-5). Parents provide an important role in the sport process, providing logistical and other types of support to the young athletes.

There are two forms of negative parental behavior at the POC. First, parents interfere with group decisions in the early years of sport participation and, secondly, high parental expectations, pressure to play professionally and the level of recognition they crave can undermine participation.

"...I see that: more expectation in the parents than in the athletes (...) they (parents) follow as the expectation grows bigger, and when they are just under 17 or 18, it is quite understandable"(POC-7).

\section{School integration}

Parents have a generalized consensus over the recognition of the importance of school over sport: “... football can... is a positive complement. I see sport practice as, since it is kept in its proper place as a complement and not as a priority" (POC-7).

Furthermore, statements from POC parents point to the idea that the athletes' school system is difficult to reconcile with the sport system, society does not accommodate and provide support to that particular structural reality: “...I think there's no connection between school and clubs and Im not talking particularly of club X" (POC-5); as more modern societies already conceive the notion of complementarity between these two systems.

"...we go to a more advanced society and everything related to culture, sports, they have everything organized and every kid has a sport education and music education..."(POC-2). 


\section{Proximal processes and social interactions}

\section{Climate and values}

Adults consider the athletes as an important part of the clubs' sport, "...athletes are, let's say, the most important part in all this process..." (POC-1). Football is a space where some important social values, important in community life, come together. They have the perception of a climate of positive commitment between the different participants operating in the club's academy: "... all of them collaborate, some work better than others but, like in every place, they know the difficulties they live with and like it!" (POC-4). Social recognition and the status of playing at the club reinforce the club's overall importance. They recognize the strong will of young people in pursuing professionalism: “...everybody dreams, if everything is right, dreams of reaching the club's professional squad and I think they work for it, some more, some less...”(POC-2).

\section{Social relations and efficacy}

Interpersonal relations between adults are considered positive, having an impact on the lives of everyone involved in the academy's everyday life “...people here work a lot contributing with voluntary work, they are dedicated" (POC-7). In fact, although practices vary, parents of both clubs emphasize voluntary work and ascribe great importance to the clubs' structural and organizational inefficiency, with a direct impact on young people's development.

"Every management worries about things (...) like obviously having a field to train on. Therefore, that little contribution should be made; they (the coaches) don't have the capacity to do it..."(POC-4).

\section{Sport context and achievement}

\section{Identity and experiences}

Although the image and notability of the club is recognized, two major difficulties arise: the financial and the infra-structural. The club has existed over a long time and the many influences of modern society have contributed to clubs' loss of identity. Concomitantly, parents indicate that the club has to count significantly on the education of young athletes, in order to construct its identity, "Club $X$ was a very representative club in a wide range of disciplines; it has been losing its eclecticism over the years" (POC-1).

\section{Community integration}

Experiences of sport are mediated by the social context of the place where a club is located. The POC is separate from the city, with weak links to the surrounding community, who lack any kind of identification with the club. Parents insist on the need to mobilize more people in the neighborhood in order for a full and complete intervention in society to be successful.

Sporting opportunities in these deprived areas have a strong influence on the family's structure, because they provide opportunities for young people's development: “...because they have good living conditions and pay to play there, automatically your son will play, mine is from a socially deprived neighborhood and therefore can't play...”(POC-2).

\section{Organization and structure}

According to the parents, orderly organization and stability is not perceived as being beneficial to the academy structure. The organization is perceived as poor, with few resources available. There is a clear gap between professional soccer and the training of young people.

"For me $X$ has youth training because it is stylish, because youth training exists for a long time and new board members have seen that there has to be youth training”(POC-6).

\section{Discussion}

From the study, researchers were able to differentiate two characteristics at the club. First, despite being called professional they were struggling with structural difficulties and some problems with internal organization. Second, parents still con-sider the club to be a positive influence in youngster's lives, with a strong competitive spirit and positive relationships inside the club.

The study points out that parents, with or without specific roles in the clubs' structure, have an influence on young people's sporting careers and expectations. Knowing that the different roles of social agents influence, for example, motivation [11], parents in the POC, although recognizing some deficiencies in the clubs' organization, ascribe great importance to the clubs' efficacy of support. Depending on context, the clubs' diverse identities in the region and dependency on public structures often outweigh their possibility of sustainability and the demands they make on young athletes [23].

However, these deficits clearly influence young people's opportunities to compete and a clear line separates these environments. Parents' perception of their children's desire for professionalism brings into play social goals such as status, recognition and a sense of belonging, which fosters a more demanding competitive environment. Parents clearly perceive that the search for professionalism is itself an objective that young athletes benefit from as it engages them in more determined and persistent types of behavior.

Literature shows that more positive perceptions of social relationships are associated with more positive motivational outcomes, taking into account parent-peer group and friendship variables in combination [24]. This is also true of the contribution of social goal orientations toward an understanding of youngster's interest in and enjoyment of sport [6]. It is reported in the literature that these feelings appear to change in relation to the game's dynamics and contextual circumstances [15]. Parents share and influence the emotions their young athletes experience in a professionalized sport environment.

It is known that sport participation is associated with a range of personal and social developmental benefits. Accordingly, parents perceive the club's climate as a place for the construction of social values inherent to sport participation, given the particular competitive environment that exists in the club.

Parents can have a negative influence, namely, by exerting pressure to perform and forcing professional aspirations on their sons; but on the other hand, they can be supportive, fundamentally recognizing the social importance of sport in the family and the inherent skills that youngsters can learn from it.

Another study [4] provided the ambivalent remark concerning adult participation and resembles the study [25] where. In fact, parents in sport environment tend to see their influence in two ways. Firstly, as social behavior that may affect ultimately the degree to which someone will persist in a given activity [26]; and, secondly, as the understanding that parental support may influence young people's relation to sport, in the sense of adolescent-parent attachment relationships [27].

Assuming that three particular assets (positive identity, empowerment, and support) are important to focus on in youth sport programs [28] reflects what young people perceive their specific context to be supposed to be. Parents refer to values such as resilience, sense of belonging, and responsibility as well as respect for others and social equilibrium as the main social skills, the characteristics of which differ from those of more regional and less competitive clubs. Furthermore, athletes benefit from these sport experiences as these assets prove themselves to be life skills when considering aspects like time management, more control over constraints and difficulties, and 
persistence. In this sense, parents are conferring an educational value to sport that can potentially be of life-long benefit to their sons.

In fact, environmental resources (autonomy, social support from the coach, and performance feedback) have been related to performance among talented young soccer players [29]. In these years of early investment, the role of follower and supporter becomes more apparent [30]. The later years in the athletes' development are characterized by a more autonomous relationship of parents towards their sons. Concomitantly to this fact, results from participant observation showed more oriented and focused informational support from parents. This evidence is found in Côté's [30] work, where, during the investment years, parents respond to the various demands and expectations placed on their child-athlete by fostering an optimal learning environment rather than creating new demands or pressure.

The study also shows through direct observation that parents are more directly involved in the early and middle years (i.e., the sampling and specializing years) and become less involved in the elite years (i.e., the investment years) of athletic talent development [14]. In accordance, these specific parental behaviors change as a function of the stage of talent development the child experiences [2].

Acknowledging that achievement-driven contextual practice and professional aspiration is perceived as an intentional important modeling mechanism in POC youth training, is itself influenced by parents' behavior and beliefs in relation to their sons.

\section{Conclusions}

The study shows that parental influence is an important sport mechanism and has an impact on youth sport involvement. This influence assumes different levels of significance during the sport years with particular relevance to the specializing phase where competitive and performance focus behaviors are predominant. Stressing the supportive role taken on by parents in these professional environments, the study shows parents' educational beliefs reflected in some lifelong learning social skills found in sport. Further studies should compare these results with those of parents who have young athletes participating in both team and individual sports. Researchers should also enlarge the number of participants in order to allow for more transferability to other studies.

Only quality-based action in organized sport will enable young people to fully experience the benefits and values of (continued) participation in organized sport. Parents are important social actors in talent development programs as they can have a powerful influence on young athletes' expectations and attitudes in demanding competitive environments of this kind. Future studies should direct attention to the family microsystem and its connections to sport-related behaviors in the process of talent development in young people.

\section{Acknowledgements}

The present manuscript was partially presented at the Business and Social Science Research Conference: Paris 2012: Paris, France.

\section{Literature}

1. Coakley J. (2006). The good father: parental expectations and youth sports. Leisure Studies 25, 153-163.

2. Côté J., Baker J., Abernethy B. (2007). Play and practice in the development of sport expertise. In G. Tenenbaum, R.C. Eklund (Eds.), Handbook sport psychology (pp. 184-202). New York: Wiley.

3. Fraser-Thomas J.L., Côté J., Deakin J. (2005). Youth sport programs: an avenue to foster positive youth development. Physical Education Sport Pedagogy 10, 19-40.

4. Bengoechea E.G., William W.B. (2007). On the interpersonal context of adolescent's sport motivation. Psychology of Sport and Exercise 8, 195-217.

5. Jõesaar H., Hein V., Hagger M.S. (2011). Peer influence on young athletes' need satisfaction, intrinsic motivation and persistence in sport: a 12-month prospective study. Psychology of Sport and Exercise 12, 500-508.

6. Allen J.B. (2011). Social motivation in youth sport. Journal of Sport and Exercise Psychology 25, 551-567.

7. Bronfenbrenner U. (2001). The bioecological theory of human development. In N.J. Smelser, P.B. Baltes (Eds.), International encyclopedia of the social and behavioral sciences (pp. 6963-6970). New York: Elsevier.

8. Bronfenbrenner U., Evans G. (2000). Developmental science in the 21st century: emerging questions, theoretical models, research designs and empirical findings. Social Development 9, 115-125.

9. Holt N., Tamminen K.A., Black D.E., Mandigo J.L., Fox K.R. (2009). Do youth learn life skills through their involvement in high school sport? Journal of Sport and Exercise Psychology 31, 37-59.

10. Holt N.L., Kingsley B.C., Tink, L.N., Scherer J. (2011). Benefits and challenges associated with sport participation by children and parents from low-income families. Psychology of Sport and Exercise 12, 490-499.

11. Keegan R.J., Harwood C.G., Spray C.M., Lavallee D.E. (2009). A Qualitative investigation exploring the motivational climate in early career sports participants: coach, parent and peer influences on sport motivation. Psychology of Sport and Exercise 10, 361-372.

12. Wurth S., Lee M.J., Alfermann D. (2004). Parental involvement and athletes' career in youth sport. Psychology of Sport and Exercise 5, 21-33.

13. Hoyle R.H., Leff S.S. (1997). The role of parental involvement in youth sport participation and performance. Adolscence 32, 233-243.

14. Lauer L., Gould D., Roman N., Pierce M. (2010). Parental behaviors that affect junior tennis player development. Psychology of Sport and Exercise 11, 487-496.

15. Holt N., Tamminen K.A., Black D.E., Sehn Z.L., Michael P.W. (2008). Parental involvement in competitive youth sport settings. Psychology of Sport and Exercise 9, 663-685.

16. Krippendorff K.H. (2004). Content Analysis: An Introduction to its Methodology ( $2{ }^{\text {nd }}$ edition). Thousand Oaks, CA: Sage.

17. Atkinson P., Hammersley M. (2007). Ethnography. Principles in practice ( $3^{\text {rd }}$ edition). London: Routledge, Taylor \& Francis Group.

18. Corbin J., Strauss A. (2008). Basics of qualitative research: Techniques and procedures for developing grounded theory ( $3^{\text {rd }}$ edition). Thousand Oaks, CL: Sage Publications.

19. Lessard-Hérbert M., Goyette G., Boutin G. (2008). Recherche qualitative ( $3^{\text {rd }}$ edition). Lisboa, Portugal: Instituto Piaget.

20. Neuman W.L. (2003). Social Research Methods (5 ${ }^{\text {rd }}$ edition). Upper Saddle River: Prentice Hall. 
21. Maxwell J.A. (2005). Qualitative Research Design: An Interactive Approach. Thousand Oaks, CL: Sage Publications.

22. Bronfenbrenner U., Morris P. (1998). The ecology of developmental process. In W. Damon, R.M. Lerner (Eds.), Handbook of Child Psychology. Theoretical Models of Human Development (pp. 993-1023). New York: John Wiley.

23. Knop P., Wylleman P., Theeboom M., Martelaer K., Hoecke J.V., Van Heddegem L. (1999). The role of contextual factors in youth participation in organized sport. European Phyical Education Review 5, 153-168.

24. Ullrich-French S., Smith A.L. (2006). Perceptions of relationships with parents and peers in youth sport: Independent and combined prediction of motivational outcomes. Psychology of Sport and Exercise 7, 193-214.

25 Gershgoren L., Tenenbaum G., Gershgoren A., Eklund R.C. (2011). The effect of parental feedback on young athletes' perceived motivational climate, goal involvement, goal orientation, and performance. Psychology of Sport and Exercise 12, 481-489.
26 Ryan R.M., Deci E.L. (2007). Intrinsic and extrinsic motivation in exercise and sport. In N.D. Chatzisarantis, M.S. Hagger (Eds.), Intrinsic motivation and self-determination in exercise and sport (pp. 1-19), Champaign, IL: Human Kinetics.

27. Carr S. (2009). Adolescent-parent attachment characteristics and quality of youth sport friendship. Psychology of Sport and Exercise 10, 653-661.

28. Strachan L., Côté J., Deakin J. (2009). An evaluation of personal and contextual factors in competitive youth sport. Journal of Applied Sport Psychology 2, 340-355.

29. Bakker A.B., Oerlemans W., Demerouti E., Slot B.B., Donovan K.A. (2011). Flow and performance: A study among talented Dutch soccer players. Psychology of Sport and Exercise $12,442-450$.

30. Côté J. (1999). The influence of the family in the development of talent in sport. The Sport Psychologist 13, 395-417.

Submitted: March 6, 2013

Accepted: June 6, 2013 